\title{
Women and computers. Effects of stereotype threat on attribution of failure
}

\author{
Sabine C. Koch *, Stephanie M. Müller, Monika Sieverding \\ University of Heidelberg, Department of Psychology, Hauptstrasse 47-51, 69117 Heidelberg, Germany
}

\section{A R T I C L E I N F O}

Article history:

Received 10 January 2008

Received in revised form 16 May 2008

Accepted 26 May 2008

Available online $\mathrm{xxxx}$

\section{Keywords:}

Stereotype threat

Gender

Attribution of failure

Computer domain

College-age students

\begin{abstract}
A B S T R A C T
This study investigated whether stereotype threat can influence women's attributions of failure in a computer task. Male and female college-age students ( $n=86,16-21$ years old) from Germany were asked to work on a computer task and were hinted beforehand that in this task, either (a) men usually perform better than women do (negative threat condition), or (b) women usually perform better than men do (positive condition), or (c) they received no threat or gender-related information (control group). The final part of the task was prepared to provide an experience of failure: due to a faulty USB-memory stick, completion of the task was not possible. Results suggest a stereotype threat effect on women's attribution of failure: in the negative threat condition, women attributed the failure more internally (to their own inability), and men more externally (to the faulty technical equipment). In the positive and control conditions, no significant gender differences in attribution emerged.
\end{abstract}

(c) 2008 Elsevier Ltd. All rights reserved.

\section{Introduction}

Computer skills are key qualifications in the professional world (Todman, 2000). Yet, women are generally found to use computers and the Internet to a lesser extent than men do (Cooper \& Weaver, 2003). In addition, a social stereotype exists that men are more competent at computer use than women are. This study investigated whether stereotype threat can be a factor contributing to the differential attribution patterns in a computer task in collegeage students and can thus eventually lead to lesser computer use or more ready resignation in the use of computers by women. We focused on the attribution patterns of men and women after failure as important prerequisites for their persistence to solve computer problems.

Although the access of women to computers has increased substantially since the 1980s and early 1990s (Imhof, Vollmeyer, \& Beierlein, 2007), a gender gap in computer use still exists across all age groups and cultures, which seems to be strongest in high school and college students (Li \& Kirkup, 2007; Papastergiou \& Solomonidou, 2005; Whitley, 1997). Colley and Comber (2003) compared recent findings on computer experience and attitudes of students (of age 11-12 and 15-16 years) within a period of 10 years. Along with gender differences in computer attitudes, boys were still found to use the computer more frequently in nonschool contexts (e.g., playing games) than girls did. Boys liked computers more and were more self-confident in using computers. In both studies, 15-16-year-old girls had the least positive attitude toward computers.

\footnotetext{
* Corresponding author. Tel.: +49 6221 547297; fax: +49 6221547325 .

E-mail address: sabine.koch@urz.uni-heidelberg.de (S.C. Koch).
}

A similar difference was also shown by the OECD-report of the PISA study (2005), which compiled data about the educational conditions and performance levels of pupils worldwide. Despite the existing gender equality in computer access, 15-year-old boys owned a computer more often, used a computer more frequently for programming, playing games, or for entertainment, and spent more time on the Internet than coeval girls did. Girls and women, on the other hand, had less self-confidence in handling the computer, particularly in complex tasks such as preparing multimedia presentations. Given that computer use has a positive impact on school math grades (Rocheleau, 1995), these findings can imply disadvantages for girls (OECD, 2005).

What are the reasons for this gender gap? Factual barriers to access and differences in the use of computers have substantially decreased (Cooper, 2006; Cooper \& Weaver, 2003; Todman, 2000) or even vanished (Wasserman \& Richmond-Abbott, 2005). Furthermore, there are no physical or cognitive obstacles that might disadvantage one gender group over the other. Normally, men and women should be equally suited for carrying out professional skills in the computer domain. The possible reasons for women not living up to their potential are the lack of female role models who use computers (Marx \& Roman, 2002), gender-specific differences in support from parents and teachers (Busch, 1996), and gender specificity of the vast majority of computer software (Cooper, 2006). Potential psychological obstacles inhibiting the computer use by girls and women are unfavorable computer attitudes (Anderson, Lankshear, Courtney, \& Timms, 2008; Lee, 2003; Shashaani, 1997; Whitley, 1997), low or missing computer self-efficacy (e.g., Cassidy \& Eachus, 2002; Jackson, Ervin, Gardner, \& Schmitt, 2001), particularly in high school students (Whitley, 1997), computer anxiety (Chua, Chen, \& Wong, 1999), and 
unfavorable attribution patterns (Dickhäuser \& Stiensmeier-Pelster, 2002; Nelson \& Cooper, 1997; Rozell \& Gardner, 1999). Our study focuses on the aspect of unfavorable attribution patterns.

\subsection{Gender differences in attributions of failure}

In an early study, Deaux and Emswiller (1974) found that the (successful) performance of male stimulus persons was more likely to be attributed to their skills (internal attribution), whereas the performance of the female stimulus persons was more likely to be attributed to luck (external attribution). Studies that tried to replicate these findings have yielded diverse results (e.g., Hill \& Augoustinos, 1997; Swim \& Sanna, 1996). Some studies focused on gender-specific attribution patterns in the self-attributions of success and failure (Burgner \& Hewstone, 1993; Nelson \& Cooper, 1997; Rozell \& Gardner, 1999; Whitley, McHugh, \& Frieze, 1986). For example, Dickhäuser and Stiensmeier-Pelster (2002) conducted two studies to investigate the gender differences in self-related attribution patterns in the computer domain. They provided different scenarios, such as "imagine that you cannot open a file you have previously saved on a disk". Participants then had to name the reasons for this event. The authors confirmed the hypothesized pattern: men preferred the external causal attribution "faulty disk", women preferred the internal attribution "lack of own knowledge". In a second study, the authors found that lack of own knowledge or ability resulted in a higher levels of shame and lower expectations of success. Thus, the affective valence of the computer was directly related to attribution patterns. However, will attribution patterns be differentially visible between men and women, when the stereotype related to "women and computers" is activated to different degrees? This research question can be addressed by choosing a stereotype threat approach to gender in the computer domain.

\subsection{Influence of stereotypes on performance: the stereotype threat paradigm}

Smith, Morgan, and White (2005) have demonstrated that there is a stereotype that women do worse at computers. The stereotype threat paradigm (Steele, 1997; Steele \& Aronson, 1995) puts forth that people belonging to minority groups suffer from performance impairments when a negative task-relevant stereotype concerning their ingroup becomes salient. When minority group members perform a difficult task in an area, in which the ingroup is considered weak, they feel at risk of confirming the stereotype. This psychological pressure can lead them to underperform. A growing body of research has shown this effect for the domain of "women and math performance” (e.g., Spencer, Steele, \& Quinn, 1999). Women, who were told that they were about to take up a math test, where men usually perform better than women do, typically underperformed in the test. In contrast, women typically perform better when told that in this test there are no gender differences (Spencer et al., 1999). For the stereotype threat to be effective, a number of conditions need to be fulfilled: (a) individuals need to show a certain degree of identification with the domain (DI) on the one hand, and, on the other hand, the social group that is subject to the threat; (b) the task needs to have a high level of difficulty to truly differentiate between the stereotyped groups; and (c) the stereotype needs to be of a certain relevance to the situation, in which participants encounter themselves while taking the test (Steele, 1997).

To date, the stereotype threat theory has been only rarely applied to gender in the computer domain. We found two studies: Cooper (2006) had students organize a presentation in Power Point and showed that female students primed with their identity as a woman immediately before a computer task (by writing a report about social life on campus, dating, partying, etc.), performed worse than those who were primed with their identity as a student (i.e., by writing a report about courses and assignments). Mauch (2008) showed that implicit threat caused by the group gender composition had direct effects on the performance at the computer: women performed best in same-sex groups, whereas men performed best in mixed-sex groups. So far, no study has addressed the influence of stereotype threat on computer-related attribution patterns.

\subsection{Our study}

The goal of our study was to test the differences in attribution of failure after stereotype threat in 16-21-year-old students of the "Gymnasiale Oberstufe" in the German school system (i.e., 11th to 13th grade). The study innovatively tested the psychological influence of stereotypes on gender differences in the computer domain, and attribution patterns of failure following the threat. For the main manipulation, we implemented the negative threat condition in the conventional manner, by informing the participants that men usually outperformed women in this computer test. In addition, we introduced a positive condition to investigate whether the positive information about women's test results can prevent a self-handicapping attribution of failure in women. A number of studies showed that the stereotyped group's performance increased after having been informed that their social group is expected to perform well on the task (e.g., Cadinu, Maass, Frigerio, Impagliazzo, \& Latinotti, 2003; Stangor, Carr, \& Kiang, 1998). In our study, we wanted to know whether this would also be valid for women's use of more beneficial attribution patterns after failure. Finally, we provided no threat-related information to the control group.

In a quasi-experimental $2 \times 3$-design ( $\mathrm{sex} \times$ threat condition), we tested the following hypotheses: (a) women in the negative threat and in the control condition attribute failure in a computer-related task internally, to their own inability, and (b) women in the positive condition and men in all three conditions attribute the failure externally, to the faulty technical equipment (Deaux \& Emswiller, 1974; Dickhäuser \& Stiensmeier-Pelster, 2002). In our analysis, we controlled the influence of computer self-efficacy, computer-related intrinsic motivation, and practical computer knowledge at baseline.

\section{Method}

\subsection{Sample}

Forty-seven men and 50 women participated in the study $(n=97)$. They were all students from the "Gymnasiale Oberstufe" in German schools (i.e., 11th-13th grade) in and around Heidelberg, Germany, aged between 16 and 21 years $(M=17.77$; $\mathrm{SD}=0.98$ ). Half of the participants were from three schools near the University, the others were asked to participate in the pedestrian zone in front of the University Psychology Department, because of the beginning school vacation. Students were randomly assigned to the experimental conditions, matched by gender. Participants received a chocolate bar as a reward for their participation. Eleven participants did not show sufficient domain identification (i.e., "a person's positive phenomenological experience with, and perceived self-relevance of a domain") (Smith et al., 2005; see below). Thus, 86 participants were included in the final analyses (44 men, 42 women; aged 16-21 years; $M=17.77 ; \mathrm{SD}=1.01$ ). Debriefing was provided via e-mail, the week after the experiment, to prevent students from exchanging content-related information regarding the study, while the experiment was still going on. 


\subsection{Test materials}

\subsubsection{Stereotype threat manipulation}

The following wording was used to provide the central threatrelated information: in the negative threat condition "Women have previously performed worse than men have in this test" (Frauen haben bei diesen Aufgaben im Vergleich zu Männern bisher schlechter abgeschnitten; cf. Keller, 2002). In the positive condition "Women have previously performed better than men have in this test" (Frauen haben bei diesen Aufgaben im Vergleich zu Männern bisher besser abgeschnitten). For the control group, no additional information was given.

\subsubsection{Technical failure induction}

A USB-memory stick (256 MB RAM) was provided to the students. Their task was to save a file to the memory stick. However, the driver of the memory stick was not installed, making the successful completion of the task impossible.

\subsection{Instruments and scales}

We conducted a pretest with 50 students from two schools in Heidelberg (different from the schools of the main study), to select adequate and efficient instruments to control the influential variables. The results suggested retaining 6 out of 13 tasks, assessing the practical computer knowledge (PRACOWI; Naumann, Richter, \& Groeben, 2001), and 10 out of 29 items from the computer self-efficacy scale by Durndell, Haag, and Laithwaite (2000). We further assessed computer ownership, access, and the use of computers (in years and hours per week). The final questionnaire included 29 items on various scales as follows.

\subsubsection{Practical computer knowledge}

Six pretested items of the PRACOWI (Naumann et al., 2001; see Appendix) were administered in the multiple-choice format. Cronbach's $\alpha$ was 0.63 in both the pretest and experiment.

\subsubsection{Computer self-efficacy}

Ten items of the short version of Durndell's computer self-efficacy scale (Durndell et al., 2000; own translation), ranging from 1 not at all to 5 - very much, were used in our study. We selected five easy items ("I feel confident ..." "... moving the cursor across the monitor screen", “...calling up a data file to view on the monitor screen”, “... printing a document”, “... using the computer to write a letter or essay", and "... deleting files that are no longer needed") and five expert items ("I feel confident ..." “....writing simple programs for the computer", "... using the computer to analyze number data”, “. . . troubleshooting computer problems”, “. . . understanding terms relating to computer hardware”, and "....understanding terms relating to computer software"). Four items addressing specific skills needed in this study ("I feel confident ... “. . .using a USB-memory device”, “... finding a specific page on the Internet", “...handling new software", and "...solving everyday computer problems") were added. Cronbach's $\alpha$ was 0.86 in both the pretest and the experiment.

\subsubsection{Computer-related motivation}

We developed two items to assess the computer-related intrinsic motivation of the participants, since earlier studies have shown that intrinsic motivation leads to a better learning performance (Lepper \& Malone, 1987). On a scale from 1 - not at all to 6 - very much, participants were asked to estimate how much they were generally motivated to work at the computer ("I am generally very motivated to work at the computer"), and how much they were presently motivated to work at the computer ("At this moment, I am very motivated to work at the computer"). Cronbach's $\alpha$ was 0.84 .

\subsubsection{Domain identification (DI)}

Following stereotype threat theory, it is important that the participants identify with the respective domain to a certain degree (Cadinu et al., 2003; Aronson, Lustina, Good, \& Keough, 1999). Smith et al. (2005) have developed an instrument to measure the domain identification in the computer domain (see definition given earlier). In their study, the authors showed that the participants viewed the IT field as a specifically male domain. Our own German translation of this scale yielded an internal consistency of Cronbach's $\alpha=0.88$ in the pretest ( $n=50)$, and 0.84 in the experiment $(n=97)$. Sample items of the seven-item scale were: "Are computers an integral part of your life?", and "How much fun do you have when working at the computer?", on a scale from 1 not at all to 5 - very much. We selected participants, who scored a minimum of 13 points on this questionnaire (range of 7-35 points), using a $10 \%$ cut-off value, which led to a reduction of our sample size, from 97 to 86 participants.

\subsection{Procedure}

The experiment consisted of four main parts. In the first part, participants were asked to complete a questionnaire addressing computer use, access, ownership, computer self-efficacy, practical computer knowledge, computer-related intrinsic motivation, and domain identification. In the second part, the central threat-related information was provided to the participants in writing. There were three conditions: providing information either to threaten women's and enhance men's performance (negative threat condition), to enhance women's and threaten men's performance (positive condition), or to evaluate performance without any additional information (control condition). In the third part of our study, participants were asked to search a PDF document on the Internet. They received information about the author and the title, and had $3 \mathrm{~min}$ to search. Then, they were asked to rename and save the document on the desktop. After the document was saved to the desktop, participants were asked to save the file to the faulty USB-memory stick, which was in fact not possible. Participants were asked to provide a causal explanation for this failure. We were interested in the attribution patterns of the participants (internal vs. external) with respect to the failure. In the end, participants provided demographic data.

\subsection{Data reduction and statistical analyses}

The total scores of the practical computer knowledge items from the PRACOWI, the computer self-efficacy items, and the computer-related motivation items were calculated. Attribution statements after failure were categorized either into internal or external by two independent female raters (Cohen's $\kappa=0.72$ ). For the effects of stereotype threat on attribution of failure, we computed a binary logistic regression.

\section{Results}

\subsection{Descriptive results: gender differences in computer-related variables}

\subsubsection{Computer access, ownership, and use}

There were no gender differences in computer access. However, men owned a computer more often $\left(\chi^{2}(1,97)=10.92, p<0.01\right)$, were more likely to know the type of processor they possessed $(84 \%, N=37)$, and were more often equipped with the latest 
technology $\left(\chi^{2}(2,97)=16.79, p<0.01\right)$ than women were $(43 \%$; $N=13$ ). On average, men had used computers for more years than women had $(t(95)=-2.07, p<0.01 ;$ MMen $=6.3$, SDMen $=2.8$; MWomen $=5.4$, SDWomen $=2.2$ ); and used them for more hours per week $(t(95)=-3.99, p<0.01 ; M M=13.8, S D M=10.3, M W=$ 7.2, $S D W=5.5)$.

\subsubsection{Computer knowledge, domain identification, computer self- efficacy, and computer-related motivation}

Men reported a significantly higher computer self-efficacy $(t(95)=-4.94, \quad p<0.01 ; \quad M M=3.8, \quad S D M=0.50 ; \quad M W=3.60$, $S D W=0.40)$, identified themselves more with the computer domain $(t(95)=-4.41, p<0.01 ; M M=3.40, S D M=0.50 ; M W=2.70$, $S D W=0.70)$, and scored higher in the computer knowledge test (PRACOWI) than women did $(t(95)=-5.00, p<0.01 ; M M=4.3$, $S D M=1.6 ; M W=2.8, S D W=1.4)$. While the majority of women achieved only half of the points ( 3 out of 6 ) in the PRACOWI test, the majority of men scored generally higher on the test and answered more than half of the questions correctly. Moreover, men had a higher computer-related intrinsic motivation to learn something new at the computer than women had $(t(95)=-2.24$, $p<0.05 ; M M=4.0, S D M=1.1 ; M W=3.5, S D W=1.1$ ).

\subsubsection{Associations between variables}

Computer domain identification was positively associated with computer ownership $(r(85)=0.36 ; p<0.01)$, computer self-efficacy $(r(85)=0.49 ; p<0.01)$, computer-related intrinsic motivation $(r(85)=0.65 ; p<0.01)$, practical computer knowledge (PRACOWI) $(r(85)=0.29 ; \quad p<0.01)$, and external attribution of failure $(r(85)=0.26, p<0.05)$. Weekly hours of computer use (higher in men) were positively correlated with computer self-efficacy $(r(85)=0.35 ; p<0.01)$, practical computer knowledge (PRACOWI) $(r(85)=0.30 ; p<0.01)$, and external attribution patterns $(r(85)=0.24 ; p<0.05)$.

Sex was positively correlated with domain identification $(r(85)=0.43 ; \quad p<0.01), \quad$ computer ownership $(r(85)=0.27$; $p<0.05)$, weekly hours of use $(r(85)=0.38 ; p<0.01)$, computer self-efficacy $(r(85)=0.43 ; p<0.01)$, practical computer knowledge (PRACOWI) $(r(85)=0.45 ; p<0.01)$, and external attribution of failure $(r(85)=0.28 ; p<0.01)$; with men showing higher values in all areas than women did (two-sided test). Participants who spent more time with the computer showed higher computer self-efficacy. Computer-related intrinsic motivation was positively correlated with computer self-efficacy $(r(85)=0.32 ; p<0.01)$. Computer self-efficacy was positively correlated with practical computer knowledge (PRACOWI) $(r(85)=0.52 ; p<0.01)$. Both variables were positively related to external attribution of failure with $r(85)=0.36 ; p<0.01$ (PRACOWI) and $r(85)=0.37 ; p<0.01$ (computer self-efficacy).

\subsection{Inferential test: the impact of stereotype threat on attribution of failure}

All participants completed the search task (finding the PDF document) within a time frame of $3 \mathrm{~min}$. The analysis of external vs. internal attribution of failure required a non-parametric test, owing to the nominal scaling of the criterion variable. We computed a binary logistic regression where attribution was assigned the value of 0 for internal and 1 for external. Results are thus an indicator of the degree of external attribution. In the logistic regression, motivation, computer self-efficacy, and practical computer skills were entered as possible predictors of (external) attribution of failure. Sex (male vs. female), the positive condition (positive vs. control group), and negative threat condition (negative vs. control group) were used as further predictor variables. We also computed the interactions of threat condition and sex with the reference cat-
Table 1

Influence of stereotype threat on attribution: results of logistic regression $(n=86)$

\begin{tabular}{lllll}
\hline & $p$ & $O^{\mathrm{a}}$ & \multicolumn{2}{l}{$95 \%$ confidence interval for $O R$} \\
\cline { 4 - 5 } & & & Lower value & Upper value \\
\hline Motivation & 0.346 & 1.07 & 0.93 & 1.24 \\
Self-efficacy & 0.373 & 1.14 & 0.86 & 1.51 \\
PRACOWI & 0.038 & 1.58 & 1.03 & 2.42 \\
Sex $^{\mathrm{b}}$ & 0.211 & 3.34 & 0.50 & 22.15 \\
Threat $^{\mathrm{c}}$ & 0.357 & Referent & & \\
Pos. condition & 0.583 & 0.62 & 0.11 & 3.41 \\
Neg. threat & 0.364 & 2.29 & 0.38 & 13.66 \\
Sex $\times$ threat & 0.022 & Referent & & 5.65 \\
Sex $\times$ pos. condition & 0.568 & 0.49 & 0.04 & 0.36 \\
Sex $\times$ neg. threat & 0.008 & 0.02 & 0.001 & \\
Constant term & 0.040 & 0.01 & & \\
& & & &
\end{tabular}

Note: Internal attribution was coded with 0 and external attribution with 1 . A mode was computed for participants with domain identification $>13$. In the model with the independent variables, computer-related intrinsic motivation, computer selfefficacy, and PRACOWI, $29 \%$ of the variance could be explained following the work of Cox and Snell (1989) and 38\% following Nagelkerke (1991). All variables had been introduced in Step 1.

a $O R=$ Odds ratio.

b Women were coded with 0 , men with 1 .

c Control condition was coded with 0 , positive condition with 1 , and negative threat with 2 .

egories of female gender and control condition. The regression model showed a highly significant model fit $\left(\chi^{2}(8,86)=28.85\right.$; $p<0.001)$. Practical computer knowledge had a significant influence on attribution $(p<0.05)$ : the higher the PRACOWI score, the more likely was the person to attribute externally (Table 1 ). There was a significant effect of sex $\times$ threat condition overall, and of sex $\times$ negative threat on attribution (Table 1 ). Only in the negative threat condition, women attributed the failure more internally than men did $(p<0.01 ; d=1.24)$, compared with the women in the control condition $(p<0.05 ; d=1.12)$. In all other conditions, no gender differences in the attribution of failure emerged (Fig. 1).

\section{Discussion}

In this study, the stereotype threat paradigm was applied to the computer domain assuming that computer competence - particularly in handling technical problems - would be viewed as a male domain. Our focus was on attribution patterns after stereotype threat. Participants were students aged between 16 and 21 years - an age group for which the IT-related gender gap has been demonstrated internationally. Descriptive results showed no gender differences in computer access. However, men more often owned a computer, were more often equipped with the latest technology, and were using the computer more frequently than women were (in hours per week and in years). Moreover, men had a higher intrinsic motivation to use the computer before taking the test. Women, on the other hand, reported less frequent computer use, which was associated with less practical computer knowledge and less computer self-efficacy. Overall, we observed that a gender gap in the computer domain still exists among German college-age students.

With respect to our focus, findings were consistent with our hypothesis - after having been exposed to the negative threat, women attributed the failure with the faulty memory stick more internally than men did, and more than the women in the control group did. When presented with the information that women normally do worse in the computer task, women blamed themselves for the failure more often, whereas men rather blamed the faulty technical equipment (Dickhäuser \& Stiensmeier-Pelster, 2002). Since computer users are confronted regularly with failure-prone technical challenges, such as error messages, 


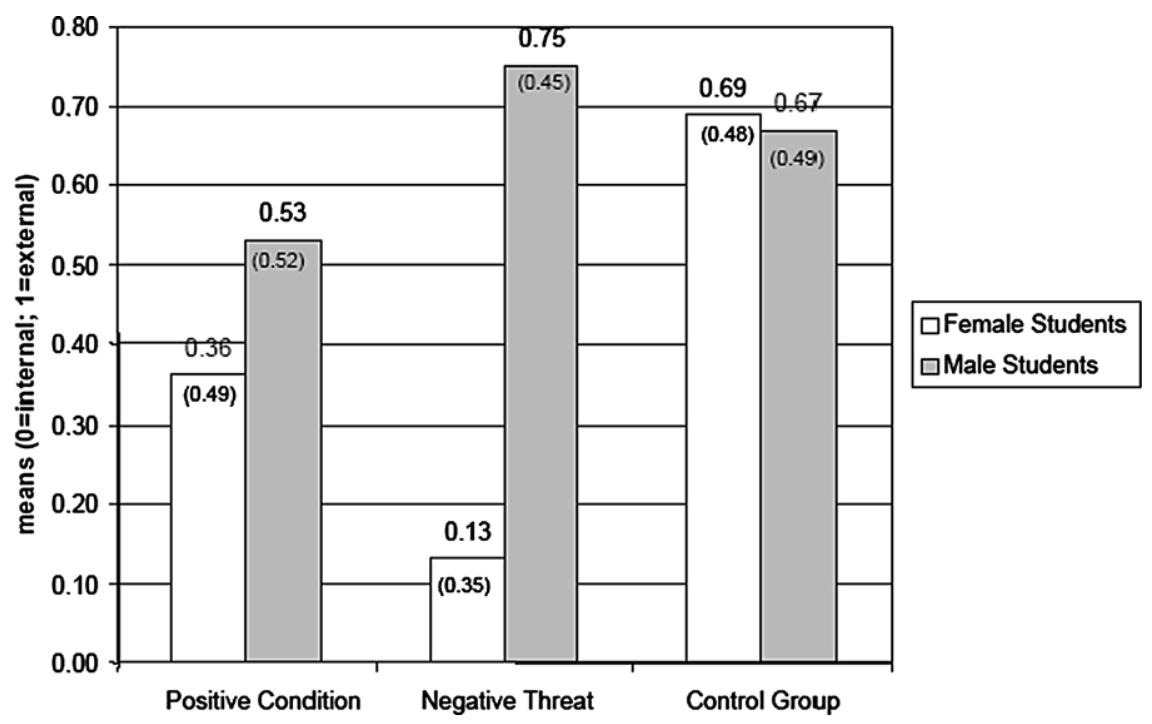

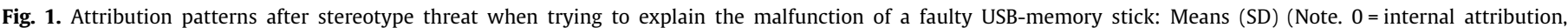


(women vs. men in the negative threat condition)).

shutdowns, installation problems with new software or new hardware (printers, external drives, etc.), unfavorable attribution patterns can have a pervasive influence on self-related variables, such as computer self-efficacy or learned helplessness. Low computer self-efficacy can perpetuate through self-fulfilling prophecy mechanisms (Cooper, 2006) and can thus lead to an increase in anxiety, a loss of interest (Anderson et al., 2008; Nelson \& Cooper, 1997), a decrease of use, and a loss of computer competence in women.

Could the gender differences in attribution have resulted from the observed differences in the IT-related abilities, beliefs, and motivation? The logistic regression showed that motivation and computer self-efficacy did not significantly affect the external or internal attribution of the failure (Table 1). However, practical computer knowledge (measured with the PRACOWI) had an impact on the attribution, in addition to the impact of the threat condition. Specifically, participants with higher practical computer knowledge had a higher probability to attribute the failure externally, compared with those with lower practical computer knowledge. However, the threat manipulation had a significant influence on attribution, controlling for the practical computer knowledge. Regression analysis thus revealed two effects that may lead to an unfavorable attribution of failure: little practical computer knowledge and - for women only - a stereotype threat condition, in which the competence of women with computers is questioned. Since we did not control for the computer use and domain identification in the logistic regression, we cannot exclude that those variables would have exerted an additional influence on the attribution patterns. Yet, it was not possible to include these variables into the model owing to the high multicollinearity. We thus selected the more psychology- and education-related variables for inclusion in the logistic regression analysis.

On a theoretical level, our results developed a bridge between attribution theory and stereotype threat theory. Maladaptive attribution patterns can be caused by stereotype threat in the minority group (in our study, women), and can be a point of reference for their future performance. The direct threat in our study led to similar results than the more indirect threat of other recent studies, manipulating gender-role context (Cooper, 2006) or sex composition of the classroom (Crombie \& Armstrong, 1999; Inzlicht \& Ben-Zeev, 2000; Mauch, 2008), whose findings suggest creating more gender-homogeneous classroom settings for IT-trainings.
One critical case for gender-stereotypic behavior seems to be the occurrence of technical difficulties with the computer or other technical equipment. Thus, related studies could, for example, simulate computer problems and measure differential reactions of men and women towards those problems. Further, given the importance of the variable of computer self-efficacy, this measure should be included in pre-/post-designs to account for the possible changes caused in tests taken under threat. For a better control of the effects of implicit stereotype threat, a nullification condition (telling participants that there are no gender differences in the task at hand) should be additionally included.

Practical implication resulting from the findings of this study are: (a) to strengthen the practical computer knowledge of women, for example, by training them in handling technical difficulties, (b) to avoid stereotype threat-prone situations, such as direct information about comparably better achievements of men in a relevant test, and (c) to strengthen the self-confidence of female students in the computer domain, by teaching them functional and self-protective attribution patterns. Reattribution trainings are offered in many countries worldwide, yielding a possibility for the effective strengthening of women's self-confidence (e.g., Ziegler \& Heller, 1997). Teachers, parents, and peers should support and encourage women's participation in digital developments that are useful for their professional lives, and help to prevent dysfunctional attribution patterns in computer-related tasks.

\section{Acknowledgements}

We thank Ruben Matterne for methodological consultation, Nils Pfeiffer for helping with the data collection, Claudia Pischke for language revisions, Anne Maass for valuable comments, and all students who participated in this study. Correspondence concerning this paper should be addressed to Sabine C. Koch, Department of Psychology, University of Heidelberg, Hauptstrasse 47-51, 69117 Heidelberg, Germany; email: sabine.koch@urz.uni-heidelberg.de.

\section{Appendix. Test of Practical Computer Knowledge (PRACOWI- Short Version)}

Translation of six items out of the 13-item German test "Praktisches Computer Wissen" (PRACOWI; Naumann et al., 2001), pretested as psychometrically suitable for pupils. 
This is a questionnaire about practical computer-knowledge (i.e., knowledge that is relevant when you use or work with a computer). Below, you will find six problems that might occur while working with a computer. For example:

0. You have been warned about the virus "Good Times". Presumably, the content of your hard drive would be deleted if you open an email with this subject line. You receive this email. What do you do?

a) I will switch off the computer immediately and get an up-to-date antivirus program.

b) I will open the email and assume that my antivirus program deletes the virus.

c) This is a hoax. There should be no problem reading or deleting this email.

d) I will press "check viruses" in my mailing program to remove the virus.

e) I don't know.

Your task for each of the problems is to choose the most likely alternative from the answers provided. If you think the "Good Times"-mail is a hoax, please check the corresponding box. If you do not know how to solve the described problem, do not guess the answer, but check "I don't know". Please read all alternatives closely and then choose your answer, you have enough time.

1. Your mouse does not work and you want to close the program that is open. What do you do?

a) I will close the program pressing the buttons 'Ctrl' + 'End' Alternati,yely the program can be closed pressing the buttons 'Alt' + 'F3'.

b) I will close the program pressing the button 'Ctrl' and in the meantime pressing the buttons 'End' + 'Enter'. Alternatively, the program can be closed pressing the buttons 'Alt' + 'F6'.

c) I will close the program pressing the buttons 'Shift' and 'End'. Alternatively, the program can be closed pressing the buttons 'Alt' + 'F5'.

d) I will close the program pressing the button 'Alt' and in the meantime pressing the buttons ' $\mathrm{F}$ ' and ' $\mathrm{X}$ ' after each other. Alternatively, the program can be closed pressing the buttons 'Alt' + 'F4'.

e) I don't know.

2. You want to have quick access to a newly installed program in Windows XP and you want to use a faster way than the Start menu. What do you do?

a) I will generate a link to the program on the desktop, using the right mouse button.

b) I will add the program to 'favorites'.

c) I will install the program directly on the desktop.

d) I will assign a combination of buttons to the program in the Windows data explorer.

e) I don't know.

3. You know that there is a certain program installed on your computer, but you can not open it the usual way. How can you solve this problem?

a) I will re-install the program.

b) I will use the Explorer searching for the program folder and open the *.exe-file of the program with a double click.

c) Programs which cannot be opened the 'usual way' are not compatible with the operating system. I will get a new version of the program adapted to my operating system.

d) I will insert the program to the program folder using system control.

e) I don't know. 
4. You receive a document as a zip-archive. What do you do?
a) I will open the document as usual using my word processing program.
b) I will unpack the program using Windows data explorer.
c) I will displace the file on my desktop using the mouse - in that way, the program is automatically
unpacked.
d) I will change the extension of the file from *.zip to Word extension *.doc. Then it becomes
possible to open the file in Word.
f) I don't know.

5. You would like to send an image via email. What do you do?

a) I will choose 'send via email' using my image processing program.

b) I will upload the image into my word processing program and send it from there.

c) I will convert the image into email format and send it afterwards.

d) I will add the file as an attachment to a regular email.

e) I don't know.

\begin{tabular}{|lc|}
\hline 6. Your computer crashed and you want to restart it as gently as possible. What do you do? & . \\
a) I will press the 'reset' button. & 0 \\
b) I will press the buttons 'Ctrl' + 'Alt' + 'Del'. & 0 \\
c) I will press the buttons 'End' + 'Enter'. & $\circ$ \\
d) I will switch the computer off and turn it on again. & $\circ$ \\
e) I don't know.
\end{tabular}

\section{References}

Anderson, N., Lankshear, C., Courtney, L., \& Timms, C. (2008). 'Because it's boring, irrelevant and I don't like computers': Why female secondary school students avoid professionally-oriented ICT subjects. Computers and Education, 50, 1304-1318.

Aronson, J., Lustina, M. J., Good, C., \& Keough, K. (1999). When white men can't do math: Necessary and sufficient factors in stereotype threat. Journal of Experimental Social Psychology, 35, 29-46.

Burgner, D., \& Hewstone, M. (1993). Young children's causal attributions for success and failure: 'Self-enhancing' boys and 'self-derogating' girls. British Journal of Developmental Psychology, 11, 125-129.

Busch, T. (1996). Gender, group composition, cooperation, and self-efficacy in computer studies. Journal of Educational Computing Research, 15, 125-135.

Cadinu, M., Maass, A., Frigerio, S., Impagliazzo, L., \& Latinotti, S. (2003). Stereotype threat: The effect of expectancy on performance. European Journal of Social Psychology, 33, 267-285.

Cassidy, S., \& Eachus, P. (2002). Developing the computer user self efficacy (CUSE) scale: Investigating the relationship between computer self-efficacy, gender and experience with computers. Journal of Educational Computing Research, 26, 133-153.

Chua, S. L., Chen, D., \& Wong, A. F. L. (1999). Computer anxiety and its correlates: A meta-analysis. Computers in Human Behavior, 15, 609-623.

Colley, A. M., \& Comber, C. (2003). Age and gender differences in computer use and attitudes among secondary school students: What has changed? Educational Research, 45, 155-165.

Cooper, J. (2006). The digital divide: The special case of gender. Journal of Computer Assisted Learning, 22, 320-334.

Cooper, J., \& Weaver, K. D. (2003). Gender and computers. Understanding the digital divide. New York: Erlbaum.

Cox, D. R., \& Snell, E. J. (1989). Analysis of binary data (2nd ed.). London: Chapman \& Hall.

Crombie, G., \& Armstrong, P. I. (1999). Effects of classroom gender composition on adolescents' computer-related attitudes and future intentions. Journal of Educational Computing Research, 20, 317-327.
Deaux, K., \& Emswiller, T. (1974). Explanations of successful performance on sexlinked tasks: What's skill for the male is luck for the female. Journal of Personality and Social Psychology, 29, 80-85.

Dickhäuser, O., \& Stiensmeier-Pelster, J. (2002). Erlernte Hilflosigkeit am Computer? Geschlechtsunterschiede in computerspezifischen Attributionen [Learned helplessness at the computer? Gender differences in computer-related attribution]. Psychologie in Erziehung und Unterricht, 49, 44-55.

Durndell, A., Haag, Z., \& Laithwaite, H. (2000). Computer self efficacy and gender: A cross cultural study of Scotland and Romania. Personality and Individual Differences, 28, 1037-1044.

Hill, M. E., \& Augoustinos, M. (1997). Re-examining gender bias in achievement attributions. Australian Journal of Psychology, 49, 85-90.

Imhof, M., Vollmeyer, R., \& Beierlein, C. (2007). Computer use and the gender gap: The issue of access use motivation and performance. Computers in Human Behavior, 23, 2823-2837.

Inzlicht, M., \& Ben-Zeev, T. (2000). A threatening intellectual environment: Why females are susceptible to experiencing problem-solving deficits in the presence of males. Psychological Science, 11, 365-371.

Jackson, L. A., Ervin, K. S., Gardner, P. D., \& Schmitt, N. (2001). Gender and the Internet: Women communicating and men searching. Sex Roles, 44, 363379.

Keller, J. (2002). Blatant stereotype threat and women's math performance: Selfhandicapping as a strategic means to cope with obtrusive negative performance expectations. Sex Roles, 47(3-4), 193-198.

Lee, A. C. K. (2003). Undergraduate students' gender differences in IT skills and attitudes. Journal of Computer Assisted Learning, 19, 488-500.

Lepper, M. R. \& Malone, T. W. (1987). Intrinsic motivation and instructional effectiveness in computer-based education. In R. E. Snow \& M. J. Fair (Eds.). Aptitude, learning and instruction (Vol. 3, pp. 255-286). Hillsdale, NJ: Erlbaum.

Li, N., \& Kirkup, G. (2007). Gender and cultural differences in Internet use: A study of China and the UK. Computers \& Education, 48(2), 301-317.

Marx, D. M., \& Roman, J. S. (2002). Female role models: Protecting women's math test performance. Personality and Social Psychology Bulletin, 28(9), 1183-1193.

Mauch, M. (2008). Auf den Spuren des Digital Divide: Chancengleichheit durch Selbstkategorisierung [Tracing the digital divide: Equal opportunities via selfcategorization]. Berlin: dissertation.de, Verlag im Internet. 


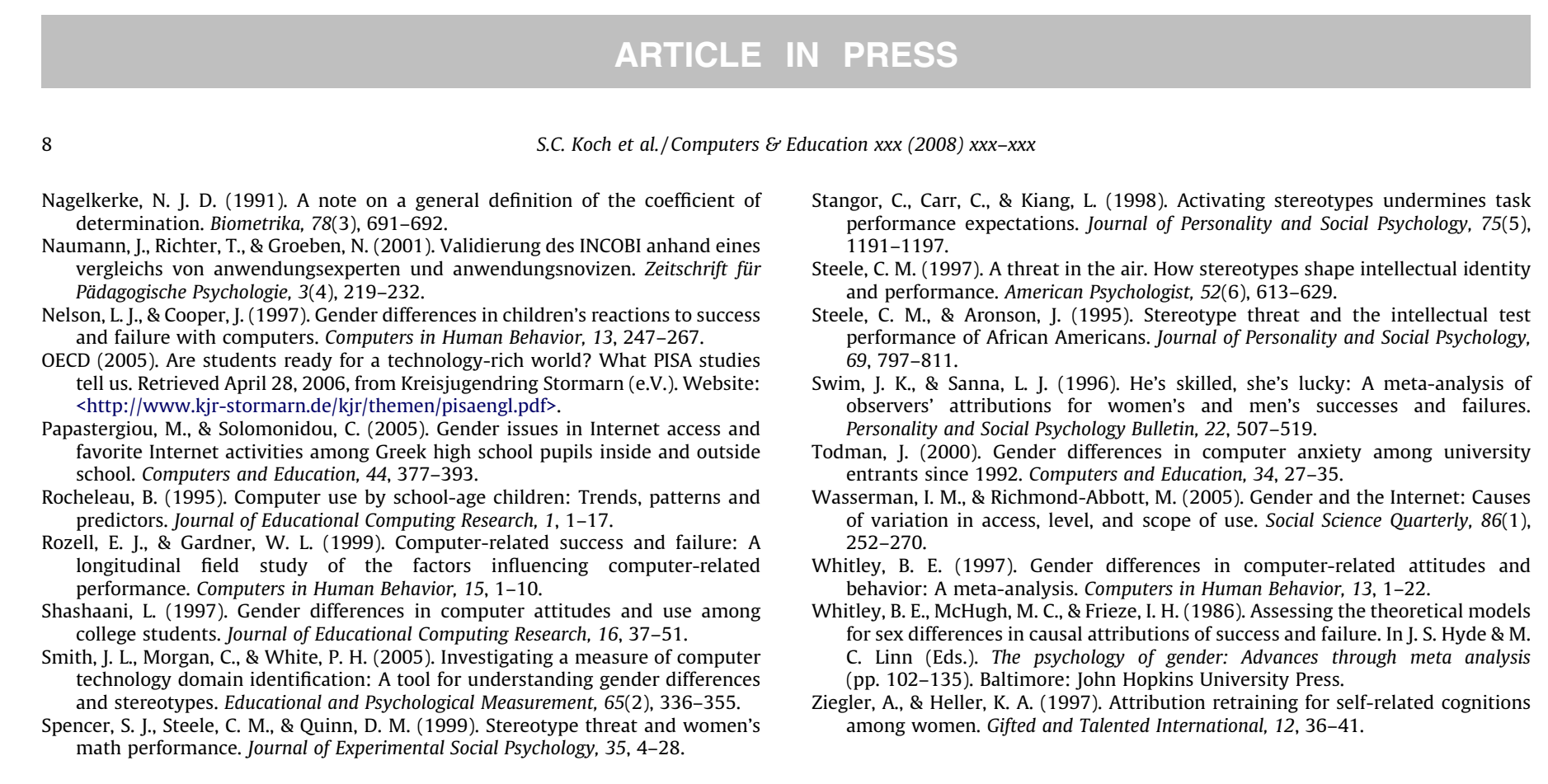

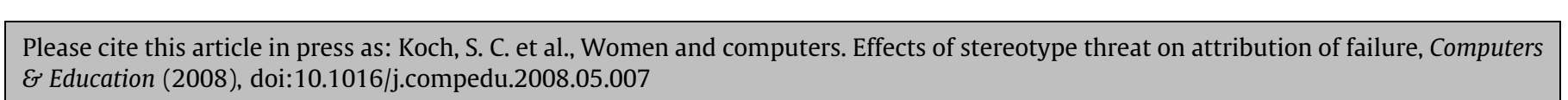

